\title{
Proteção do dano oxidativo hepático induzido por ferro pelo extrato aquoso da planta Plectranthus barbatus
}

PERANDIN, D.'; MAIOLI, M.A.'; SANTOS, P.R.S.2; PEREIRA, F.T.V.2; MINGATTO, F.E. ${ }^{2}$ 'Laboratório de Bioquímica Metabólica e Toxicológica (LaBMeT) e "Laboratório de Morfologia da Placenta e Embrião (L@MPE) do Campus de Dracena da Universidade Estadual Paulista "Júlio de Mesquita Filho", Rodovia Comandante João Ribeiro de Barros, km 651, CEP: 17900-000, Dracena - SP - Brasil fmingatto@ dracena.unesp.br

\begin{abstract}
RESUMO: Plectranthus barbatus Andrews (Lamiaceae) é uma planta muita utilizada na medicina popular para o tratamento de doenças gastrointestinais e hepáticas. O objetivo do presente trabalho foi estudar o efeito protetor do extrato aquoso de $P$. barbatus (EAPB) sobre os danos hepáticos causados pela sobrecarga de ferro provocada pelo ferro-dextran em ratos. $O$ tratamento com ferro-dextran induziu uma redução significativa na concentração de glutationa reduzida nos animais tratados em relação ao grupo controle e o tratamento prévio dos animais com o EAPB protegeu o fígado do efeito provocado pelo ferro neste parâmetro. Com relação à lipoperoxidação, houve aumento significativo na concentração de malondialdeído (MDA) nos animais tratados em relação ao controle, entretanto, quando os animais receberam o tratamento prévio com o EAPB, houve redução significativa na concentração do MDA. A análise histopatológica mostrou que o grupo tratado com ferro-dextran apresentou grânulos de ferro no citoplasma das células de Kupffer com alargamento das mesmas e algumas com os núcleos hipertróficos. O tratamento prévio com EAPB resultou no desaparecimento dos sinais de danos às células de Kupffer sem nenhum núcleo hipertrófico, mas com a presença de grânulos de ferro totalmente fagocitados, o que demonstra uma aparência morfológica normal. Portanto, o EAPB pode ser útil na prevenção de danos hepáticos induzidos por sobrecarga de ferro.
\end{abstract}

Palavras-chave: Plectranthus barbatus, ferro, fígado, toxicidade, estresse oxidativo.

ABSTRACT: Protection against hepatic oxidative damage induced by iron by the aqueous extract of Plectranthus barbatus. The Plectranthus barbatus Andrews (Lamiaceae) is a plant largely used in folk medicine to treat gastrointestinal and liver diseases. The objective of this work was to study the protective effect of the aqueous extract of $P$. barbatus (EAPB) against damage caused by iron overload induced by iron dextran in rat liver. Treatment with irondextran induced a significant reduction in the glutathione levels in treated animals compared to control group, and the pretreatment of animals with EAPB protected the liver from the effects caused by iron in this parameter. With respect to lipid peroxidation, a significant increase in the malondialdehyde (MDA) levels in treated animals compared to control was observed; however, when the animals were pretreated with EAPB, there was a significant reduction in the MDA levels. Histopathological analysis showed that the group treated with iron-dextran showed iron granules in the cytoplasm of the Kupffer cells and some of them presented enlarged nuclei. The group previously treated with EAPB showed the disappearance of the signs of damage to the Kupffer cells with no nucleus hypertrophy but with the presence of iron granules completely phagocytosed by these cells, which showed a normal morphological appearance. Therefore, the EAPB may be useful in the prevention of liver damage induced by iron overload.

Key words: Plectranthus barbatus, iron, liver, toxicity, oxidative stress.

\section{INTRODUÇÃO}

Plectranthus barbatus Andrews (Lamiaceae) conhecida no Brasil popularmente como boldo, falso boldo, boldo africano, boldo-do-reino, malva santa

e boldo-da-terra é usado largamente na medicina popular, sendo que o chá produzido pela maceração de suas folhas ajuda no combate a males do sistema 
digestivo, respiratório, circulatório e distúrbios nervosos (Lukhoba et al., 2006). São descritas, ainda, ações contra infecções (Gupta et al., 1993), atividades abortivas, anticoncepcionais (Almeida \& Lemonica, 2000), e analgésica (Chifundera, 2001). A planta é também utilizada para tratar a gastrite e espasmos intestinais (Câmara et al., 2003), náusea (Hamill et al., 2003), dor de estômago, epilepsia e convulsões (Schaneberg \& Khan, 2003; Fernandes et al., 2012) e apresenta, ainda, ação antioxidante (Tamasiro et al., 1998) e atividades citotóxicas (Costa \& Nascimento, 2003).

Devido à sua interposição entre o trato digestivo e a circulação geral do organismo, o fígado desempenha uma função central no metabolismo. Ele recebe grandes quantidades de nutrientes e substâncias exógenas (xenobióticos) que são absorvidos por meio do trato digestivo e veia porta. Entre as principais funções hepáticas estão: a captação de aminoácidos, lipídios, carboidratos e vitaminas, com subseqüente armazenamento, conversão metabólica e liberação no sangue e bile. O fígado é também o principal órgão envolvido na biotransformação dos xenobióticos, com capacidade de converter compostos hidrofóbicos em hidrossolúveis, mais facilmente eliminados pelo organismo (Guillouzo \& Guguen-Guillouzo, 2008).

O ferro é vital para todos os organismos vivos pela sua participação em múltiplos processos metabólicos essenciais, incluindo o transporte de oxigênio, síntese de DNA e transporte de elétrons. $O$ equilíbrio de ferro no corpo é cuidadosamente regulado para assegurar que a absorção compense as perdas corporais deste elemento. Ao contrário de outros metais, é altamente conservado pelo organismo (Aisen \& Listowsky, 1980; Goswami et al., 2002). A sobrecarga de ferro causa dano tecidual e eventual falência de órgãos e, sendo o fígado o alvo primário, freqüentemente tem sido observado em pacientes fibrose hepática e cirrose (Gramm \& Ruddell, 2005). Como demonstram estudos in vitro e in vivo (Britton et al., 1987; Britton et al., 2002), a peroxidação de lipídeos da membrana celular provavelmente está por trás dessa toxicidade.

Pacientes que sofrem de doenças como hemocromatose e talassemia acumulam, através de repetidas transfusões de sangue, níveis elevados de ferro nos seus órgãos vitais que, rapidamente, levam à morte por insuficiência cardíaca se não tratadas. Além disso, o ferro é também um mediador para efeitos dos radicais livres em várias outras condições patológicas, incluindo cardiopatia isquêmica e câncer (Halliwell \& Gutteridge, 1990; Hershko, 1994; Toyokuni, 1996).

A desferoxamina e a deferiprona têm sido prescritas para o tratamento de doenças causadas pela sobrecarga de ferro, porém o uso desses compostos apresenta várias limitações (Olivieri \& Britenham, 1997; Richardson, 1999; Kontoghiorghes et al., 2001) que indicam a necessidade para a busca de novas substâncias que sejam mais efetivas e menos tóxicas para os pacientes que não respondem ao tratamento ou que demonstram efeitos colaterais tóxicos após sua administração (Kontoghiorghes, 2003). Em experimentos anteriores realizados em nosso laboratório, com mitocôndrias isoladas de fígado de rato, foi demonstrado que o extrato aquoso da planta Plectranthus barbatus foi capaz de prevenir a lipoperoxidação dos lipídios de membrana, provavelmente devido ao seu efeito quelante de ferro (Maioli et al., 2010). Nesse sentido, o objetivo do presente trabalho foi estudar o efeito protetor "in vivo" do extrato aquoso da planta Plectranthus barbatus sobre os danos oxidativos causados pela sobrecarga de ferro provocada pelo ferro-dextran em fígado de ratos.

\section{MATERIAL E MÉTODO}

Preparação do extrato aquoso da planta Plectranthus barbatus foi coletada no município de Cajobi, São Paulo, Brasil (Latitude: $20^{\circ} 52^{\prime} 47^{\prime \prime}$ S, Longitude: $48^{\circ} 48^{\prime} 34^{\prime \prime}$ W). A planta foi identificada pelo Prof. Dr. Milton Groppo e um voucher foi depositado no Herbário do Departamento de Biologia da Faculdade de Filosofia Ciências e Letras de Ribeirão Preto, Universidade de São Paulo (USP), recebendo o número SPFR 10365. As folhas de Plectranthus barbatus foram colocadas para secagem em estufa de circulação de ar forçada a temperatura de $37^{\circ} \mathrm{C}$, trituradas e, ao pó adquirido $(43,8 \mathrm{~g})$, foram adicionados $10 \mathrm{~mL}$ de água destilada para cada $1 \mathrm{~g}$ de pó (10:1) e essa suspensão foi fervida por trinta minutos. Em seguida, a suspensão foi filtrada em tecido do tipo "voil" e, a solução obtida, foi concentrada por evaporação a pressão reduzida em um evaporador rotativo. O rendimento do extrato obtido foi de 40,38\%, com concentração final de 321 $\mathrm{mg} / \mathrm{mL}$. O extrato foi congelado em alíquotas a $-20^{\circ} \mathrm{C}$ e foi descongelado de acordo com a necessidade para uso neste trabalho.

\section{Animais e tratamentos}

Os animais utilizados nesse estudo foram ratos machos da linhagem Wistar com peso entre 200 e 240 g, provenientes do Biotério Central da Universidade Estadual Paulista "Júlio de Mesquita Filho", campus de Botucatu. Os mesmos foram alojados em um ambiente controlado com temperatura de $20 \pm 2^{\circ} \mathrm{C}$ com ciclo de luz de $12 \mathrm{~h}$, receberam alimentação e água ad libitum e foram divididos aleatoriamente em quatro grupos de quatro animais de acordo com cada tratamento, os quais

Rev. Bras. PI. Med., Campinas, v.17, n.1, p.9-17, 2015. 
tiveram a duração de 14 dias: Grupo 1 (controle): receberam água destilada por gavagem gástrica durante dois períodos de 7 dias consecutivos, sendo que a partir do oitavo dia receberam $2 \mathrm{~mL}$ de salina/kg de peso vivo via intraperitoneal $2 \mathrm{~h}$ após o tratamento com água destilada; Grupo 2: receberam o extrato aquoso de Plectranthus barbatus (EAPB) por gavagem gástrica (250 mg/kg de peso vivo) durante dois períodos consecutivos de 7 dias, sendo que a partir do oitavo dia receberam $2 \mathrm{~mL}$ de salina/kg de peso vivo via intraperitoneal $2 \mathrm{~h}$ após o tratamento com o EAPB; Grupo 3: receberam água destilada por gavagem gástrica durante dois períodos consecutivos de 7 dias, sendo que a partir do oitavo dia receberam ferro-dextran-salina via intraperitoneal (100 mg/kg de peso vivo) $2 \mathrm{~h}$ após o tratamento com água destilada; Grupo 4: receberam EAPB por gavagem gástrica $(250 \mathrm{mg} / \mathrm{kg}$ de peso vivo) durante dois períodos consecutivos de 7 dias, sendo que a partir do oitavo dia receberam ferro-dextran-salina via intraperitoneal $(100 \mathrm{mg} / \mathrm{kg}$ de peso vivo) $2 \mathrm{~h}$ após o tratamento com o EAPB. O tratamento com o ferro-dextran foi realizado conforme Pardo-Andreu et al., 2008, o qual foi demonstrado ser capaz de causar sobrecarga de ferro e toxicidade no fígado de rato. O protocolo experimental foi aprovado pelo Comitê de Ética para Uso de Animais de Laboratório do Campus Experimental de Dracena, Universidade Estadual Paulista "Júlio de Mesquita Filho", protocolo número 010/2008.

\section{rato}

\section{Preparação do homogenato de fígado de}

Ratos tratados e controles foram eutanasiados por decapitação e seus fígados retirados e colocados em um béquer com aproximadamente $50 \mathrm{~mL}$ de tampão fosfato de sódio, $\mathrm{pH} 7,2$, a $4{ }^{\circ} \mathrm{C}$, onde foram picotados e levados para um homogeneizador do tipo Potter-Elvehjen e homogeneizados 3 vezes por 15 segundos com intervalos de 1 minuto.

\section{Proteína}

A determinação de proteína foi realizada por meio da reação do biureto, de acordo com Cain \& Skilleter (1987), usando-se albumina de soro bovino (BSA) como padrão e expressa em mg de proteína/mL.

Determinação da concentração de glutationa reduzida (GSH) no homogenato

A determinação da GSH no homogenato do fígado dos animais tratados e controle foram realizados segundo metodologia descrita por Hissin \& Hilf, (1976) com adaptações. Em tubos do tipo "eppendorf" de $2 \mathrm{~mL}$ foram colocados $1 \mathrm{~mL}$ de meio contendo sacarose $125 \mathrm{mM}, \mathrm{KCl} 65 \mathrm{mM}$ e HEPES$\mathrm{KOH} 10 \mathrm{mM}, \mathrm{pH}$ 7,4, homogenato (1 mg de proteína) e $500 \mu \mathrm{L}$ de ácido tricloroacético $13 \%$. A mistura foi agitada e centrifugada a $9000 \mathrm{~g}$ por $3 \mathrm{~min}$. Em tubos de $5 \mathrm{~mL}$ foram colocados $1780 \mu \mathrm{L}$ de tampão contendo $\mathrm{NaH}_{2} \mathrm{PO}_{4} 0,1 \mathrm{M}, \mathrm{pH} 8,0$, com EDTA $5 \mathrm{mM}$, $200 \mu \mathrm{L}$ do sobrenadante obtido da centrifugação e $20 \mu \mathrm{L}$ de DTNB $10 \mathrm{mM}$ completando o volume final de $2 \mathrm{~mL}$; no "branco" foram adicionados $1980 \mu \mathrm{L}$ do tampão e $20 \mu \mathrm{L}$ do DTNB. Em seguida os tubos foram agitados e mantidos por 15 minutos no escuro à temperatura ambiente. A leitura foi realizada em um espectrofotômetro Beckman-Coulter modelo DU-800, no comprimento de onda de $412 \mathrm{~nm}$ e a concentração de GSH foi estimada por meio de uma curva padrão e expressa em nmol de GSH/ mg de proteína.

\section{Determinação da lipoperoxidação}

A lipoperoxidação foi determinada no homogenato do fígado dos animais tratados e controle por meio da formação do malondialdeído (MDA), o qual reage com o ácido tiobarbitúrico (TBA), conforme descrito por Buege \& Aust, (1978) com adaptações. O homogenato (5 mg de proteína) foi colocado em tubo de ensaio e foram adicionados $0,2 \mathrm{~mL}$ de SDS 8,1\% (p/v), 1,5 mL de ácido acético $20 \%(\mathrm{v} / \mathrm{v}), 1,5 \mathrm{~mL}$ de solução aquosa de TBA a $0,67 \%(p / v)$; em seguida o volume foi completado até $4 \mathrm{~mL}$ com água deionizada (Milli-Q) e a mistura colocada em banho-maria a $95^{\circ} \mathrm{C}$ por $60 \mathrm{~min}$. Após o período de incubação os tubos foram retirados e resfriados em banho de gelo e adicionado $1 \mathrm{~mL}$ de água Milli-Q e o complexo MDA-TBA foi extraído com $5 \mathrm{~mL}$ de n-butanol. Em seguida os tubos foram centrifugados a $2000 \mathrm{~g}$ por 10 minutos, a parte orgânica foi coletada e a absorvância medida a $535 \mathrm{~nm}$ em um espectrofotômetro Genesys 10UV (Thermo Spectronic, Rochester, EUA). A concentração do complexo MDA-TBA ( $\mathrm{nmol} / \mathrm{mg}$ de proteína) foi determinada utilizando-se o coeficiente de extinção molar de $1,56 \times 10^{5} \mathrm{M}^{-1}$.

\section{Processamento do material para análise histopatológica \\ Uma fração do fígado dos animais tratados} e controle foi retirada e as amostras foram fixadas em formol 10\% tamponado, $\mathrm{pH} 7,4$. Após esse período, foram realizadas lavagens para a remoção do fixador e os materiais foram submetidos ao processo de desidratação em álcool e embebidos em cera de parafina. Cortes de $5 \mu \mathrm{m}$ foram montados em lâminas de vidro e corados com hematoxilina e eosina (Humason, 1972).

Análise estatística

A significância estatística dos dados

Rev. Bras. Pl. Med., Campinas, v.17, n.1, p.9-17, 2015. 
experimentais foi avaliada pela análise de variância (ANOVA) seguida pelo teste de Dunnet para as comparações dos grupos tratados em relação ao seu controle ou pelo teste de Newman-Keuls para as comparações de vários grupos tratados em relação a estes diferentes grupos e em relação aos seus controles, utilizando-se o programa GraphPad Prism, versão 4.0 para Windows, Graphpad Software (San Diego, CA, USA). Os resultados com valor de $p<0,05$ foram considerados estatisticamente significantes.

\section{RESULTADOS}

Determinação da concentração de GSH no homogenato

De acordo com o observado na Figura 1 ocorreu uma redução significativa na concentração de GSH no homogenato de fígado dos animais tratados com ferro-dextran (G3) em relação ao grupo controle (G1), indicando que o ferro induziu a oxidação da glutationa reduzida presente no homogenato. O tratamento prévio dos animais com o EAPB (G4) protegeu o fígado do efeito provocado pelo ferro com relação a esse parâmetro.

\section{Determinação da lipoperoxidação}

Como demonstrado na Figura 2, houve aumento significativo na concentração de MDA no homogenato de fígado dos animais tratados em relação ao controle (G1), indicando um aumento na lipoperoxidação, sendo que o maior aumento

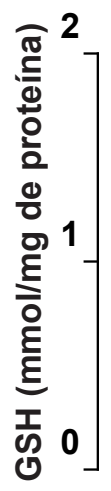

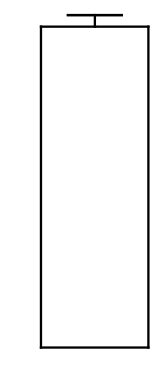

G1

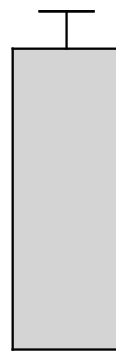

G2

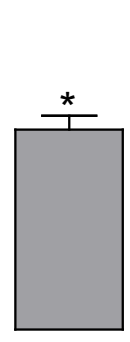

G3

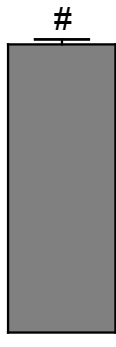

G4
FIGURA 1. Concentração de glutationa reduzida (GSH) no homogenato de fígado de ratos, onde G1 = animais controle (salina + salina), G2 = animais tratados com EAPB e salina, G3 = animais tratados com salina e ferro-dextran e G4 = animais tratados com EAPB e ferro-dextran. Os resultados representam a média \pm EPM de quatro animais. * Significativamente diferente do controle (G1) $(p<0,05)$, \#Significativamente diferente do grupo tratado com ferro $(G 3)(p<0,05)$. ocorreu nos animais do grupo tratado com ferrodextran (G3). Entretanto, quando os animais receberam o tratamento prévio com o EAPB, houve uma redução significativa nos níveis de MDA, demonstrando que o extrato protegeu, mesmo que parcialmente, o fígado dos animais dos efeitos provocados pelo ferro.

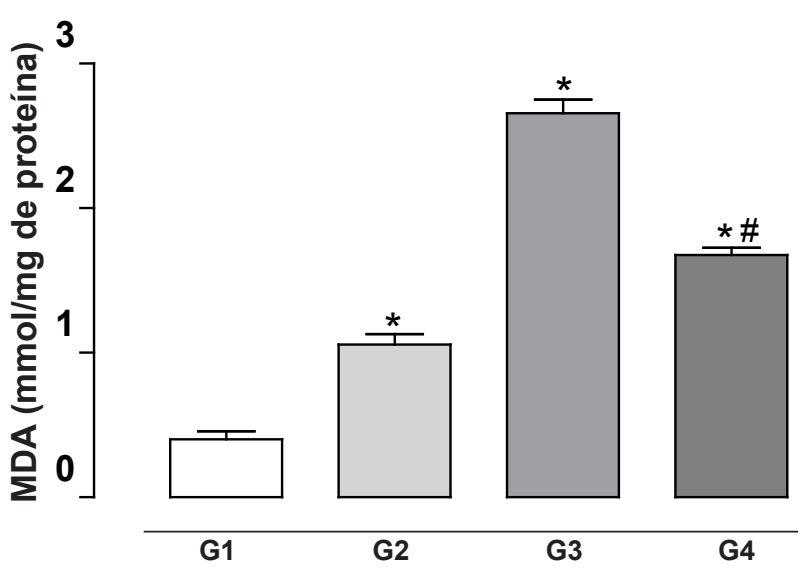

FIGURA 2. Lipoperoxidação no homogenato de fígado de ratos, onde $\mathrm{G} 1$ = animais controle (salina + salina), G2 = animais tratados com EAPB e salina, G3 = animais tratados com salina e ferro-dextran e G4 = animais tratados com EAPB e ferro-dextran. Os resultados representam a média \pm EPM de quatro animais. *Significativamente diferente do controle $(G 1)(p<0,05)$, "Significativamente diferente do grupo tratado com ferro $(G 3)(p<0,05)$.

\section{Análise Histopatológica}

A análise das lâminas histológicas do grupo controle (G1) e do grupo tratado com EAPB (G2) demonstrou que não ocorreu nenhum tipo de dano ou acúmulo de substância nas células de Kupffer (Figuras $3 \mathrm{~A}$ e B). Nos ratos tratados com ferrodextran (G3) foram observados grânulos de ferro no citoplasma das células de Kupffer com alargamento das mesmas e algumas com os núcleos hipertróficos e aparência vesicular, consistente com sua ativação (Figura $3 \mathrm{C}$ ). O tratamento prévio dos ratos com EAPB (G4) promoveu o desaparecimento dos sinais de danos às células de Kupffer provocados pelo ferro-dextran, uma vez que as mesmas apresentaram uma aparência morfológica normal com grânulos de ferro totalmente fagocitados, como pode ser observado na Figura 3D.

\section{DISCUSSÃO}

As plantas medicinais, cuja eficiência terapêutica e segurança quanto ao uso foram previamente avaliadas e comprovadas, estão

Rev. Bras. PI. Med., Campinas, v.17, n.1, p.9-17, 2015. 

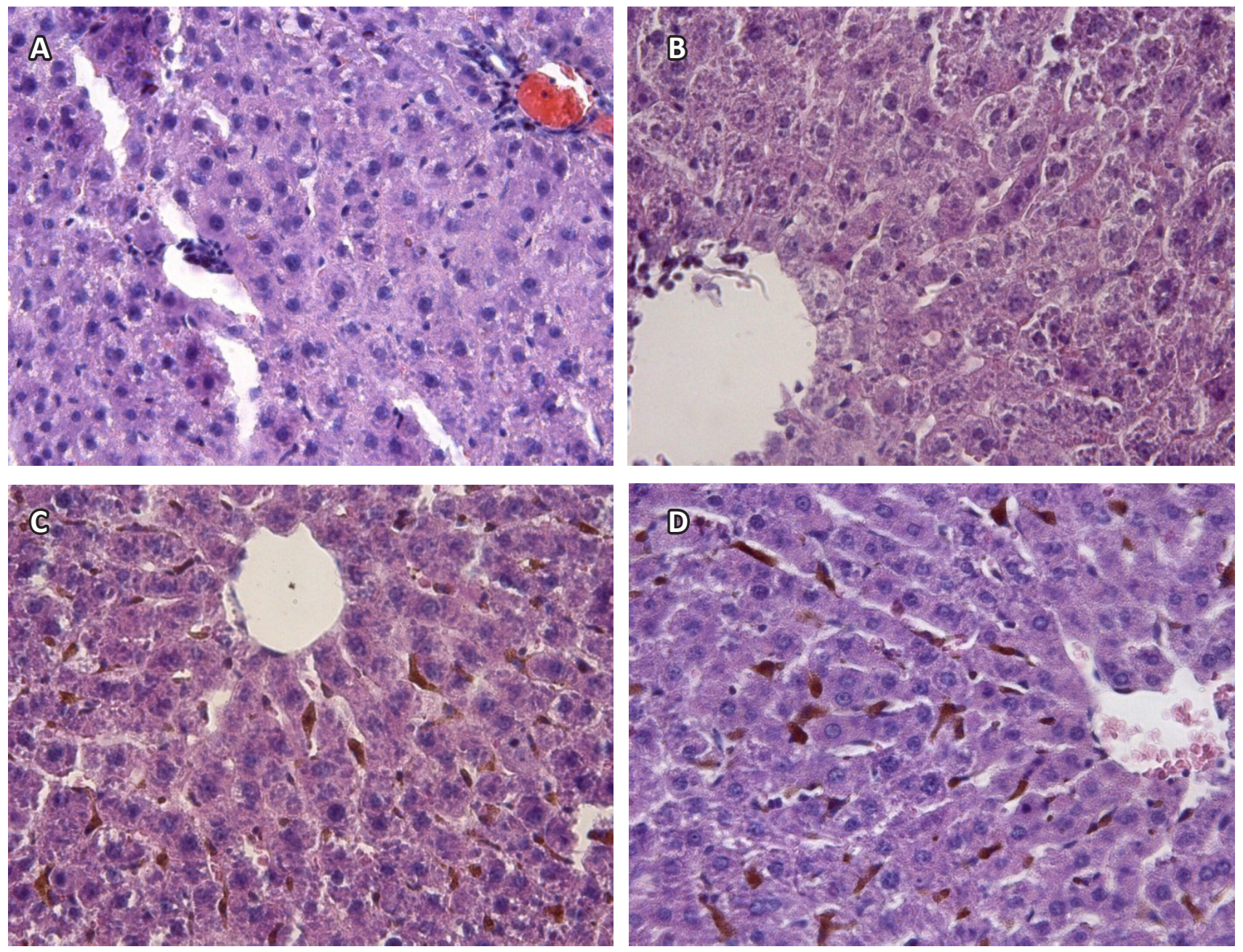

FIGURA 3. Efeito do EAPB na caracterização histopatológica de fígado de ratos tratados com ferro-dextran (400x). A, grupo controle tratado com salina; B, grupo tratado com salina mais EAPB; C, grupo tratado com salina mais ferro-dextran; D, grupo tratado com EAPB mais ferro-dextran.

cientificamente aprovadas para serem utilizadas pela população nas suas necessidades básicas de saúde, em função de sua facilidade de acesso, baixo custo e compatibilidade cultural com as tradições populares (Martins et al. 1995).

A planta Plectranthus barbatus apresenta como componentes químicos: óleo essencial (aromadendro), diterpenos (barbatol, barbatesina, cariocal, barbatusol) (Kelecon, 1983), flavonóides, esteróides e saponinas. Todavia, de acordo com Tandon et al. (1979), a composição da planta varia de acordo com a região onde é encontrada, porém não se tem certeza ainda se isso ocorre por diferenças genéticas ou climáticas. Análise por cromatografia líquida no extrato de Plectranthus barbatus, utilizado neste estudo, mostrou a predominância de compostos fenólicos semelhantes às nepetoidinas, as quais são ésteres do ácido cafeico (Maioli et al,, 2010).

O estudo sobre os mecanismos de lesão oxidativa tem, progressivamente, confirmado a ação catalítica dos metais nas reações que levam a estas lesões. O papel dos metais na formação in vitro das "espécies reativas do oxigênio" (ERO) é confirmado pelas reações de Fenton e de Haber-Weiss (Leonard et al., 2004). Embora o cobre possa também catalisar a reação de Haber-Weiss, o ferro é mais abundante no organismo e está biologicamente mais capacitado para catalisar as reações de oxidação de biomoléculas (Aust \& Miller, 1991).

É conhecido há muito tempo que em desordens por sobrecarga do ferro, a mitocôndria é um importante alvo para a toxicidade do metal, sendo os danos oxidativos da membrana mitocondrial e inibição de enzimas do ciclo do ácido tricarboxílico e metabolismo energético reconhecidos como alvos potenciais (Hershko et al. 1998).

Um aumento na produção de radicais livres ou uma redução nos níveis de antioxidantes pode resultar em lesão celular (Leonard et al., 2004). 
Esta condição é definida como estresse oxidativo, que se caracteriza por distúrbio no balanço entre oxidantes e antioxidantes em favor dos primeiros. Os oxidantes são formados, principalmente, na cadeia de transporte de elétrons mitocondrial, onde o oxigênio consumido sofre processo de redução monovalente, dando origem a intermediários extremamente reativos, as espécies reativas de oxigênio (ERO), como o oxigênio singlete $\left(\mathrm{O}_{2}{ }^{1}\right)$, o radical superóxido $\left(\mathrm{O}_{2} \cdot{ }^{*}\right)$, o peróxido de hidrogênio $\left(\mathrm{H}_{2} \mathrm{O}_{2}\right)$ e o radical hidroxil $(\cdot \mathrm{OH})$ (Cadenas \& Davies, 2000). As defesas antioxidantes foram desenvolvidas durante o processo evolutivo para interagir com estas espécies tóxicas. Os sistemas de proteção endógena são chamados de reserva antioxidante. Estas incluem principalmente, as enzimas catalase (CAT), superóxido dismutase (SOD), glutationa peroxidase (GPx), glutationa redutase (GR) e glutationa S-transferase (GST) (Yu, 1994). Os principais antioxidantes não-enzimáticos são: tocoferóis, carotenóides, flavonóides, ácido ascórbico, glutationa reduzida (GSH) e ácido úrico (Scalbert \& Williamson, 2000; Dröge, 2002). Quando ocorre desequilíbrio ente oxidantes e antioxidantes aumenta a tendência de instalação do dano oxidativo.

A glutationa reduzida (GSH, L-glutamil-Lcisteinil-glicina) está presente na maioria das células e é o tiol (-SH) não proteico mais abundante no meio intracelular (Marí et al., 2009). Sua capacidade redutora é determinada pelo grupamento tiol, presente na cisteína. A GSH pode ser considerada um dos agentes mais importantes do sistema de defesa antioxidante da célula, protegendo-a contra a lesão resultante da exposição a agentes como íons ferro (Galleano \& Puntarulo, 1995), oxigênio hiperbárico, ozona, radiação e luz ultravioleta (Deneke \& Fanburg, 1989). Além disto, diminui a susceptibilidade à lesão renal decorrente da isquemia e reperfusão (Shan et al., 1990); atua como transportadora e reservatório da cisteína e participa da detoxificação de agentes químicos e da eliminação de produtos da lipoperoxidação. Ainda, é requerida para a síntese de DNA, de proteínas e de algumas prostaglandinas (Deneke \& Fanburg, 1989).

A administração de ferro-dextran contribui para o estabelecimento de um ambiente oxidado nos tecidos do fígado e, portanto, a quantidade da glutationa reduzida (GSH) foi também utilizada para avaliar o estresse oxidativo. Foi observada uma diminuição significativa na quantidade da GSH no grupo tratado com salina mais ferro-dextran (G3), em relação ao grupo controle (G1) e uma proteção da oxidação da glutationa no grupo tratado com EAPB mais ferro-dextran (G4), em relação ao grupo tratado com salina mais ferro-dextran (G3).
Esses resultados indicam que o EAPB atua como antioxidante sendo capaz de diminuir os danos oxidativos induzidos pelo ferro.

Todos os componentes celulares são suscetíveis à ação das ERO, porém a membrana é um dos mais atingidos em decorrência da peroxidação lipídica (lipoperoxidação), que acarreta alterações na sua estrutura e permeabilidade (Mello Filho et al., 1983). Consequentemente, há perda da seletividade na troca iônica e liberação do conteúdo de organelas, como as enzimas hidrolíticas dos lisossomas, e formação de produtos citotóxicos (como o malondialdeído, MDA), culminando com a morte celular (Hershko, 1989). A lipoperoxidação também pode estar associada aos mecanismos de envelhecimento, de câncer e à exacerbação da toxicidade de xenobióticos (Shan et al., 1990; Dmitriev \& Titov, 2010). Assim como na formação das ERO, nem sempre os processos de lipoperoxidação são prejudiciais, pois seus produtos são importantes na reação em cascata a partir do ácido araquidônico (formação de prostaglandinas) e, portanto, na resposta inflamatória (Halliwell \& Gutteridge, 1990). Todavia, o excesso de tais produtos pode ser lesivo (Birben et al., 2012).

No presente trabalho, embora todos os grupos tratados tenham apresentado diferença significativa na lipoperoxidação em relação ao grupo controle (G1), o grupo tratado com EAPB mais ferrodextran (G4) apresentou uma redução significativa em relação ao grupo tratado com salina mais ferro-dextran (G3). Esses resultados demonstram que o EAPB é capaz de inibir a lipoperoxidação causada pelo ferro, provavelmente devido à sua capacidade seqüestradora do íon, diminuindo a sua forma livre. Essa capacidade do EAPB em seqüestrar o ferro livre e diminuir a lipoperoxidação foi previamente demonstrada por experimentos "in vitro" realizados em nosso laboratório utilizando mitocôndrias isoladas de fígado de rato (Maioli et al., 2010). Cabe lembrar que, embora o tratamento com boldo e salina (G2) tenha apresentado aumento significativo da lipoperoxidação em relação ao controle (G1), esse efeito não foi suficiente para causar a morte celular dos hepatócitos, uma vez que não foi observada diferença significativa na atividade sérica da enzima alanina transaminase (ALT) entre esses dois grupos (resultados não apresentados).

A sobrecarga de ferro pode produzir efeitos graves na saúde quando a capacidade de armazenamento do organismo for excedida (Britton et al., 1987). Sob estas condições, a produção de radicais livres através da geração de ferro livre é considerada uma ação importante do metal de transição, levando a danos oxidativos a biomoléculas, alterações funcionais de organelas subcelulares, e perda de viabilidade celular (Britton

Rev. Bras. PI. Med., Campinas, v.17, n.1, p.9-17, 2015. 
et al., 1987; Aust et al., 1985). Estas características de sobrecarga de ferro são observadas em vários tecidos incluindo o fígado, (Britton et al., 1987) um órgão que é responsável pelo armazenamento de cerca de um terço de todo o ferro do organismo, sendo distribuído nos hepatócitos $(98 \%)$ e em células de Kupffer, células endoteliais, lipócitos e fibroblastos (2\%) (Bacon \& Tavill, 1984).

As células de Kupffer, juntamente com outras células sinusoidais, desempenham um papel fundamental na manutenção da função hepática, em circunstâncias fisiológicas e patológicas. As principais funções das células de Kupffer incluem a fagocitose de partículas estranhas, a remoção de endotoxinas e outras substâncias nocivas e modulação da resposta imune (Arii \& Imamura, 2000). Também são conhecidas por produzirem espécies reativas de oxigênio e óxido nítrico sob estimulação, além de vários mediadores relacionados à lesão celular, ou seja, proteases e citocinas como o fator de necrose tumoral $\alpha$, interferon alfa/beta, e as interleucinas 1 e 6 (Decker, 1990). Assim, a hepatotoxicidade induzida pelo ferro, logo após o tratamento, depende da atividade das células de Kupffer, que parece ser causada pela produção de reações ligadas aos radicais livres de oxigênio e pode envolver uma liberação de citocinas pró-inflamatórias como encontrado após a administração de vários xenobióticos hepatotóxicos (Laskin et al., 1995; Blazka et al., 1995).

Conforme Pardo-Andreu et al., 2008, a administração intraperitoneal de ferro-dextran em ratos resulta na captação de ferro pelas células de Kupffer, podendo agir de duas formas: (1) pela produção de espécies oxidativas, tanto por vias direta como pela reação de Fenton, e (2) através da ativação do fator nuclear kB, produzindo mediadores fibrogênicos, citocinas pró-inflamatórias, quimiocinas e moléculas de adesão (Videla et al., 2003); estes podem ser responsáveis por danos às células de Kupffer, bem como para o aumento do número de macrófagos residentes encontrados em ratos com sobrecarga de ferro; ambos os efeitos poderiam aumentar danos nos hepatócitos.

Ao avaliar os efeitos do ferro-dextran no material histológico processado em nosso trabalho, vimos que o grupo tratado com salina mais ferro-dextran (G3), apresentou grânulos de ferro no citoplasma das células de Kupffer com alargamento das mesmas e algumas com os núcleos hipertróficos. Já o grupo tratado com EAPB mais ferro-dextran (G4), resultou no desaparecimento dos sinais de danos às células de Kupffer sem nenhum núcleo hipertrófico, mas com a presença de grânulos de ferro totalmente fagocitados pelas mesmas, 0 que demonstra uma aparência morfológica normal. Esses resultados indicam que o tratamento com
EAPB atua como hepatoprotetor sendo capaz de diminuir os danos às células de Kupffer induzidos pelo ferro.

Os resultados aqui apresentados indicam que os efeitos protetores do extrato aquoso de Plectranthus barbatus contra a sobrecarga de ferro induzida pelo ferro-dextran estão relacionados com a capacidade do extrato em diminuir os danos oxidativos induzidos pelo ferro na glutationa reduzida, sua capacidade de inibir a lipoperoxidação devido à atividade seqüestradora do ferro, provavelmente exercida pelos compostos fenólicos semelhantes à nepetoidina identificados no extrato da planta e publicados anteriormente (Maioli et al., 2010), interrompendo assim a participação do íon na reação de Fenton/Harber-Weiss e por meio da proteção aos danos às células de Kupffer. Portanto, nossos resultados sugerem que o extrato aquoso da planta apresenta potencial para ser utilizado na prevenção de danos hepáticos induzidos por sobrecarga de ferro.

\section{AGRADECIMENTO}

À Fundação de Amparo à Pesquisa do Estado de São Paulo (FAPESP), pela bolsa de iniciação científica concedida a Diego Perandin (Processo no. 2008/11292-4), e ao Laboratório de Morfologia da Placenta e Embrião da UnespDracena coordenado pela Profa. Dra. Flávia Thomaz Verechia Pereira, pelo suporte técnico na preparação e avaliação das lâminas.

\section{REFERÊNCIAS}

AISEN, P.; LISTOWSKY, I. Iron transport and storage proteins. Annual Review of Biochemistry, v.49, p.357393, 1980.

ALMEIDA, F.C.G.; LEMONICA, I.P. The toxic effects of Coleus barbatus $B$. on the different periods of pregnancy in rats. Journal of Ethnopharmacology, v.73, p.53-60, 2000.

ARII, S.; IMAMURA, M. Physiological role of sinusoidal endothelial cells and Kupffer cells and their implication in the pathogenesis of liver injury. Journal of Hepatobiliary and Pancreatic Surgery, v.7, n.1, p.40-48, 2000.

AUST, S.D.; MOREHOUSE, L.A.; THOMAS, C.E. Role of metals in oxygen radical reactions. Journal of Free Radicals in Biology and Medicine, v.1, n.1, p.3-25, 1985.

AUST, S.D.; MILLER, D.M. Role of iron in oxygen radical generation and reactions. In: Probst, G.S.; Vodicnik, M.J; Dorato, M.A.(eds). New horizons in molecular toxicology: a symposium. Bethesda, (MLD) U.S.A.: Lilly Research Laboratories, a Division of Eli Lilly and Co. by the Federation of American Societies for Experimental Biology, 1991. p.29-34. 
BACON, B.R.; TAVILL, A.S. Role of the liver in normal iron metabolism. Seminars in Liver Disease, v.4, n.3, p.181-192, 1984.

BIRBEN, E. et al. Oxidative stress and antioxidant defense. World Allergy Organ Journal, v.5, n.1, p.9-19, 2012.

BLAZKA, M.E. et al. Role of proinflammatory cytokines in acetaminophen hepatotoxicity. Toxicology and Applied Pharmacology, v.133, n.1, p.43-52, 1995.

BRITTON, R.S.; BACON, B.R.; RECKNAGEL, R.O. Lipid peroxidation and associated hepatic organelle dysfunction in iron overload. Chemistry and Physics of Lipids, v.45, n.2-4, p.207-239, 1987.

BRITTON, R.S.; LEICESTER, K.L.; BACON, B.R. Iron toxicity and chelation therapy. International Journal of Hematology, v.76, p.219- 228, 2002.

BUEGE, J.A.; AUST, S.D. Microsomal lipid peroxidation. Methods in Enzimology, v.52, p.302-310, 1978.

CADENAS, E.; DAVIES, K.J.A. Mitochondrial free radical generation, oxidative stress, and aging. Free Radical Biology and Medicine, v.29, p.222-230, 2000.

CAIN, K.; SKILLETER, D.N. Preparation and use of mitochondria in toxicological research. In: SNELL, K.; MULLOCK, B. (Ed). Biochemical Toxicology. Oxford: IRL Press, 1987. p.217-254.

CÂMARA, C.C. et al. Antispasmodic effect of the essential oil of Plectranthus barbatus and some major constituents on the guinea-pig ileum. Planta Medica, v.69, p.10801085, 2003.

CHIFUNDERA, K. Contribution to the inventory of medicinal plants from the Bushi area, South Kivu Province, Democratic Republic of Congo. Fitoterapia, v.72, p.351-368, 2001.

COSTA, M.C.; NASCIMENTO, S.C. Atividade citotóxica de Plectranthus barbatus Andr. (Lamiaceae). Revista Acta Farmacêutica Bonaerense, v.22, n.2, p.155-158, 2003.

DECKER, K. Biologically active products of stimulated liver macrophages (Kupffer cells). European Journal of Biochemistry, v.192, n.2, p.245-262, 1990.

DENEKE, S.M.; FANBURG, B.L. Regulation of cellular glutathione. American Journal of Physiology, v.257, n.4, p.L163-L173, 1989.

DMITRIEV, L.F.; TITOV, V.N. Lipid peroxidation in relation to ageing and the role of endogenous aldehydes in diabetes and other age-related diseases. Ageing Research Reviews, v.9, n.2, p.200-210, 2010.

DRÖGE, W. Free radicals in the physiological control of cell function. Physiological Reviews, v.82, n.1, p.4795, 2002.

FERNANDES, L.C.B; CÂMARA, C.C; SOTOBLANCO, B. Anticonvulsant activity of extracts of Plectranthus barbatus leaves in mice. Evidence-Based Complementary and Alternative Medicine, v.2012, 4 p., 2012. doi:10.1155/2012/860153.

GALLEANO, M.; PUNTARULO, S. Role of antioxidants on the erythrocytes resistance to lipid peroxidation after acute iron overload in rats. Biochimica et Biophysica Acta, v.1271, n.2-3, p.321-326, 1995.

GOSWAMI, T.; ROLFS, A.; HEDIGER, M.A. Iron transport: emerging roles in health and disease. Biochemistry and Cell Biology, v.80, p.679-689, 2002.

GRAMM, G.A.; RUDDELL, R.G. Hepatotoxicity of iron overload: mechanisms of iron-induced hepatic fibrogenesis. Seminars in Liver Disease, v.25, p.433-
449, 2005.

GUILLOUZO, A.; GUGUEN-GUILLOUZO, C. Evolving concepts in liver tissue modeling and implications for in vitro toxicology. Expert Opinion on Drug Metabolism \& Toxicology, v.4, p.1279-1294, 2008.

GUPTA, S.; YADAVA, J.N.S.; TANDON, J.S. Antisecretory (antidiarrhoeal) activity of Indian medicinal plants against Escherichia coli enterotoxin-induced secretion in rabbit and guinea pig ileal loop models. International Journal of Pharmacognosy, v 31, p.198-204, 1993.

HALLIWELL, B.; GUTTERIDGE, J.M.C. Role of free radicals and catalytic metal ions in human disease: An overview. Methods Enzymology, v.186, p.1-85, 1990.

HAMILL, F.A. et al. Traditional herbal drugs of Southern Uganda-II: literature analysis and antimicrobial assays. Journal of Ethnopharmacology, v.84, p.57-78, 2003.

HERSHKO, C. Mechanism of iron toxicity and its possible role in red cell membrane damage. Seminars in Hematology, v.26, n.4, p.277-285, 1989.

HERSHKO, C. Iron chelators. In: BROCK, J.H., HALLIDAY, J.W., PIPPARD, M.J., POWELL, L.W. (Ed.). Iron Metabolism in Health and Disease. London: W.B. Saunders, 1994. p.391-426.

HERSHKO, C.; LINK, G.; CABANTCHIK, I. Pathophysiology of iron overload. In: ANNALS OF THE NEW YORK ACADEMY OF SCIENCES, 850, 1998, New York. Journal Article... New York: Wyley, 1998. p.191-201.

HISSIN, P.J.; HILF, R. A fluorometric method for determination of oxidized and reduced glutathione in tissues. Analytical Biochemistry, v.74, n.1, p.214226, 1976.

HUMASON, G.L. Animal Tissue Techniques. 3.ed. San Francisco: W.H. Freeman and Co, CA, 1972, p.641.

KELECON, A. Isolation, structure determination, and absolute configuration of barbatusol; a new bioactive diterpene with a rearranged abietane skeleton from the Labiate Coleus barbatus. Tetrahedon, v.39, n.21, p.3603-3608, 1983.

KONTOGHIORGHES, G.J. Do we need more ironchelating drugs? Lancet, v.362, p.495-496, 2003.

KONTOGHIORGHES, G.J., et al. Iron overload toxicity and new therapeutic strategies with the orally effective chelating drug deferiprone (L1). Biomarkers and Environment, v.4, p.16-21, 2001.

LASKIN, D.L. et al. Modulation of macrophage functioning abrogates the acute hepatotoxicity of acetaminophen. Hepatology, v.21, n.4, p.1045-1050, 1995.

LEONARD, S.S.; HARRIS, G.K.; SHI, X. Metal-induced oxidative stress and signal transduction. Free Radical Biology and Medicine, v.37, p.1921-1942, 2004.

LUKHOBA, C.W.; SIMMONDS, M.S.J.; PATON, A.J. Plectranthus: A review of ethnobotanical uses. Journal of Ethnopharmacology, v.103, p.1-24, 2006.

MAIOLI, M.A. et al. Iron chelating-mediated antioxidant activity of Plectranthus barbatus extract on mitochondria. Food Chemistry, v.122, n.1, 203208, 2010.

MARÍ, M. et al. Mitochondrial glutathione, a key survival antioxidant. Antioxidants \& Redox Signaling, v.11, p.2685-2700, 2009.

MARTINS, E.R. et al. Plantas Medicinais. Viçosa:

Rev. Bras. PI. Med., Campinas, v.17, n.1, p.9-17, 2015. 
Imprensa Universitária, 1995. p.220.

MELLO FILHO, A.C.; HOFFMAN, M.E.; MENEGHINI, R. Cell killing and DNA damage by hydrogen peroxide are mediated by intracellular iron. Biochemical Journal, v.218, n.1, p.273-275, 1983.

OLIVIERI, N.F; BRITTENHAM, G.M. Iron chelating therapy and the treatment of thalassemia. Blood, v.89, p.739761, 1997.

PARDO-ANDREU, L.G. et al. Protective effects of Mangifera indica L extract (vimang), and its major component mangiferin, on iron-induced oxidative damage to rat serum and liver. Pharmacological Research, v.57, p.79-86, 2008.

RICHARDSON, D.R. The therapeutic potential of iron chelators. Expert Opinion on Investigational Drugs, v.8, p.2141-2158, 1999.

SCALBERT, A.; WILLIAMSON, G. Dietary intake and bioavailability of polyphenols. Journal of Nutrition, v.130, n.8, p.2073S-2085S, 2000.

SCHANEBERG, B.T.; KHAN, I.A. Quantitative analysis of forskolin in Coleus forskohlii (Lamiaceae) by reversedphase liquid chromatography. Journal of AOAC
International, v.86, p.467-470, 2003.

SHAN, X.; AW, T.Y.; JONES, D.P. Glutathione-dependent protection against oxidative injury. Pharmacology and Therapeutics, v.47, n.1, p.61-71, 1990.

TAMASIRO, V. et al. In vitro antioxidant activity of Coleus barbatus (Andr.) Benth (false boldo) and Peumus boldo (Molina) (Boldo do Chile): a comparative study. Revista de Farmácia e Bioquímica da Universidade de São Paulo, v.34, p.15-17, 1998.

TANDON, J.S. Crocetin-dialdehyde from Coleus forskohlii Briq., Labiatae. Helvetica Chimica Acta, v.62, n.8, p.2706-2707, 1979.

TOYOKUNI, S. Iron-induced carcinogenesis: the role of redox regulation. Free Radical Biology and Medicine, v.20, p.553-566, 1996.

VIDELA, L.A. et al. Oxidative stress-mediated hepatotoxicity of iron and copper: role of Kupffer cells. Biometals, v.16, n.1, p.103-111, 2003

YU, B.P. Cellular defenses against damage from reactive oxygen species. Physiologicals Reviews, v.74, n.1, p.139-162, 1994. 